\title{
Gender differences in the PUFA-fatty acid composition of membrane phospholipids in rats
}

\author{
Rebecca Grant, Stephanie Lees, Gemma Legg and Graham Burdge \\ University of Southampton, Southampton, UK
}

The PUFA composition of cell membranes is an important determinant of the biophysical properties of the lipid bilayer and, as a consequence, tissue function. The PUFA composition of plasma lipids differs between men and women ${ }^{(1)}$. In particular, the concentration of DHA (22:6n-3) is higher in females than males. It has recently been shown that that the $22: 6 n-3$ content of hepatic phospholipids is higher in adult female than male rats ${ }^{(2)}$. The present study has tested the hypothesis that gender differences in membrane phospholipidPUFA composition are tissue-specific and differ between phospholipid classes.

Male and female rats (fifteen per gender) were maintained on a diet based on AIN93M ${ }^{(3)}$ containing $9 \mathrm{~g}$ lard and $1 \mathrm{~g}$ soyabean oil/100 g feed and were killed on postnatal day 85 . Tissues were frozen immediately in liquid $\mathrm{N}_{2}$. Total lipids were extracted, phosphatidylcholine (PC) and phosphatidylethanolamine (PE) were purified by solid-phase extraction and fatty acid methyl esters prepared as described previously ${ }^{(4)}$. The amounts of individual PUFA were determined by GC and expressed as a proportion of nineteen fatty acids.

The proportions of specific PUFA in membrane phospholipids differed between genders according to tissue and phospholipid class. Linoleic acid (18:2n-6) was $27 \%$ lower in heart PC in females than in males. Arachidonic acid (20:4n-6) was higher in liver (15\%) and heart (12\%) PC in females than in males, but lower in skeletal muscle (SM; 23\%) and adipose tissue (AT; 28\%) PE. 22:6n-3 was higher in females than in males in liver PC $(63 \%)$ and PE $(38 \%)$ and in heart PC $(21 \%)$. There were no gender differences in the proportions of dihomo- $\gamma$-linolenic acid (20:3n-6), $\gamma$-linolenic acid (18:3n-3), EPA $(20: 5 n-3)$ or docosapentaenoic acid (22:5n-3) in any phospholipid class or tissue.

\begin{tabular}{|c|c|c|c|c|c|c|c|c|c|c|c|c|c|}
\hline & & \multicolumn{12}{|c|}{ Proportion of total fatty acids $(\mathrm{g} / 100 \mathrm{~g})$} \\
\hline & & \multicolumn{4}{|c|}{$18: 2 n-6$} & \multicolumn{4}{|c|}{$20: 4 n-6$} & \multicolumn{4}{|c|}{$22: 6 n-3$} \\
\hline & & \multicolumn{2}{|c|}{$\mathrm{M}$} & \multicolumn{2}{|c|}{$\mathrm{F}$} & \multicolumn{2}{|c|}{$\mathrm{M}$} & \multicolumn{2}{|c|}{$\mathrm{F}$} & \multicolumn{2}{|c|}{$\mathrm{M}$} & \multicolumn{2}{|c|}{$\mathrm{F}$} \\
\hline & & Mean & $\mathrm{SD}$ & Mean & $\mathrm{SD}$ & Mean & $\mathrm{SD}$ & Mean & $\mathrm{SD}$ & Mean & $\mathrm{SD}$ & Mean & SD \\
\hline \multirow[t]{2}{*}{ Liver } & PC & 8.0 & 2.1 & 6.9 & 1.2 & 23.7 & 5.1 & $27.2 *$ & 1.8 & 6.7 & 1.8 & $10.9 * * *$ & 1.3 \\
\hline & PE & 7.5 & 1.8 & 6.4 & 1.7 & 21.2 & 4.6 & 21.5 & 4.7 & 9.9 & 4.5 & $13.7 *$ & 3.2 \\
\hline \multirow[t]{2}{*}{ SM } & PC & 9.6 & 2.5 & 10.1 & 2.1 & 20.8 & 4.0 & 18.3 & 4.5 & 10.1 & 2.1 & 8.8 & 1.9 \\
\hline & $\mathrm{PE}$ & 8.2 & 2.4 & 8.7 & 2.1 & 13.9 & 4.5 & $10.7 *$ & 1.0 & 17.5 & 5.1 & 20.1 & 7.7 \\
\hline \multirow[t]{2}{*}{ Heart } & PC & 12.3 & 2.6 & $9.0 * *$ & 0.5 & 25.0 & 2.0 & $27.9 * *$ & 0.6 & 6.8 & 0.5 & $8.2 *$ & 0.4 \\
\hline & PE & 9.9 & 1.5 & 8.5 & 2.8 & 23.4 & 2.4 & 21.6 & 3.8 & 11.6 & 2.4 & 13.8 & 1.8 \\
\hline \multirow[t]{2}{*}{ AT } & PC & 16.7 & 1.2 & 16.6 & 1.0 & 6.5 & 2.6 & 6.8 & 2.9 & 0.5 & 0.2 & 0.4 & 0.2 \\
\hline & PE & 14.1 & 1.0 & 13.9 & 0.7 & 9.4 & 3.4 & $6.8^{* *}$ & 1.1 & 1.0 & 0.5 & 0.7 & 0.2 \\
\hline
\end{tabular}

M, male; F, female. Mean values were significantly different from those for $\mathrm{M}$ (Student's unpaired $t$ test): $* P<0.05, * * P<0.01, * * * P<0.0001$.

These data show that individual tissues exhibit gender-dependent differences in PUFA content. This finding implies that these differences are regulated at the level of the individual tissues, possibly reflecting differences in the specificity of phospholipid metabolism, and so do not reflect fatty acid supply alone. One possible implication is that any gender differences in tissue function may, at least in part, be a result of differences in membrane phospholipid composition.

This work was supported in part by the British Heart Foundation.

1. Burdge GC \& Calder PC (2006) Nutr Res Rev 19, 26-52.

2. Burdge GC, Slater-Jefferies JL, Grant RA, Chung W-S, West AL, Lillycrop KA, Hanson MA \& Calder PC (2008) Prostaglandins Leukot Essent Fatty Acids 78, 73-79.

3. Reeves PG (1997) J Nutr 127, Suppl., 838S-841S.

4. Burdge GC, Wright P, Jones AE \& Wootton SA (2000) Br J Nutr 84, 781-787. 